Research Paper

\title{
O Marketing Digital na Conexão das Relações de Consumo
} The Digital Marketing in the Consumer Relations Connection

\begin{abstract}
RESUMO
Este estudo tem como objetivo geral identificar as respostas do marketing digital no relacionamento com consumidores exigentes. Como método de abordagem, trata-se de um estudo de natureza qualitativa e quantitativa, com tipologia descritiva. Os dados foram coletados por meio de um roteiro de entrevista aplicada à gestora de uma loja de roupas femininas situada em Fortaleza, Ceará e um questionário dirigido a uma amostra de 182 clientes. Os resultados evidenciaram que a empresa se preocupa com as mudanças no modo de consumir da era digital e, enfrenta o momento de crise proporcionando melhores experiências, definindo melhor seu proposito e trabalhando a colaboração entre empresa e consumidor. Os resultados ressaltam a importância do marketing digital no objetivo da empresa de estreitar relacionamento com os clientes.
\end{abstract}

Palavras-chave: Marketing digital, Comportamento do Consumidor, Sociedade de Consumo.

* UniChristus - Centro Universitário Christus, Brasil. E-mail: tiagobraga53@gmail.com

** UniChristus - Centro Universitário Christus, Brasil. E-mail: zailaoliveira@gmail.com 


\begin{abstract}
This study aims to identify the responses of digital marketing in the relationship with demanding consumers. As a method of approach, it is a study of a qualitative and quantitative nature, with a descriptive typology. Data were collected through an interview script applied to the manager of a women's clothing store located in Fortaleza, Ceará and a questionnaire addressed to a sample of 182 customers. The results showed that the company is concerned with the changes in the way of consuming in the digital age and faces the moment of crisis providing better experiences, better defining its purpose and working on collaboration between company and consumer. The results highlight the importance of digital marketing in the company's objective of strengthening relationships with customers.
\end{abstract}

Keywords: Digital marketing, Consumer behavior, Consumer society.

Received on: 2021/04/17

Approved on: 2021/11/29

Evaluated by a double blind review system

\title{
1. INTRODUÇÃO
}

As mudanças na forma de produzir, o aumento do consumo e as demandas diante de determinados eventos, provocam modificações no mercado e fazem com que novos modelos de negócios sejam criados e os atuais sejam reformulados. Diante dessas transformações, o perfil do consumidor, no modo de pensar e de se comportar também se modifica. Em sua maioria, o consumidor consome mais emocionalmente do que racionalmente, inúmeros fatores levam as pessoas a comprarem de tal maneira, tais como o contexto social, motivos psicológicos, o estilo de vida, cultural, e a autoestima (Magids et.al., 2015).

As pesquisas revelam que o número de pessoas está crescendo. Segundo censo do Instituto Brasileiro de Geografia e Estatística (IBGE, 2019), a população brasileira passou de 190,7 milhões em 2010 para 210,1 milhões em 2019. Paralelo ao crescimento da população segue o crescimento do consumo, e mesmo em momentos de crise econômica ou de saúde pública, como se encontra o Brasil, consumir é inevitável. A média do 
consumo familiar no Brasil cresceu 1,3\% em 2018 em comparação com anos anteriores, sendo sua melhor evolução desde 2014.

Ao longo dos anos, o mercado consumidor foi se tornando entusiasta dos meios inovadores de comunicação. Segundo o IBGE (2019), o Brasil tem 70\% da população conectada à internet, o que equivale a 126,9 milhões de pessoas buscando diariamente por informações sobre os produtos, serviços e organizações presentes no seu ciclo de compra, tornando-os mais socialmente informados e conectados com as empresas. Devido à necessidade da comunicação entre empresa e cliente o marketing trabalha estratégias para possibilitar o relacionamento. Com o avanço da internet o cliente passou a ter contato mais direto com as empresas, comunicando-se e interagindo com a criação dos seus produtos e serviços, passando a cobrar mais das instituições ações que eles consideram mais responsáveis.

Contudo, diante da gravidade da crise atual de saúde pública mundial provocada pela pandemia do Covid-19, medidas restritivas foram adotadas para controle e prevenção do surto coronavírus (Bezerra et. al., 2020) causando impactos na saúde mental (Peeri et. al., 2020) e na economia (Santos, 2020). De acordo com Silva et.al. (2020) a era digital ganhou mais evidência no cenário de pandemia. Contudo, apesar do poder de compra ter sido afetado, o consumidor estabilizado financeiramente potencializou as compras via internet. Assim, durante a pandemia o consumidor se mostrou mais digital, ansioso e curioso, buscando diferentes experiências (Silva et.al., 2020).

$\mathrm{Na}$ atualidade, o consumidor detém um elevado grau de consciência, é crítico e guiado por valores, cabe às organizações satisfazer positivamente essas exigências. Por sua vez, a comunicação representa um dos principais pilares do relacionamento. E, na era digital, qualquer descontentamento é exposto rapidamente nas redes sociais. Dessa forma é importante que as empresas desenvolvam estratégias para aproximar seus clientes, atuando de forma expressiva e colaborativa diante das questões de responsabilidade pública.

Desse modo, o objetivo geral desse estudo é identificar as respostas do marketing digital no relacionamento com consumidores exigentes. Para tal foram definidos como objetivos específicos: i) analisar os processos de relacionamento com o cliente; ii) verificar a importância das práticas de gestão diante do comportamento do novo consumidor conectado; 
iii) compreender os desafios do marketing digital diante das exigências provindas do crescente consumo virtual.

Para a empresa este estudo apresenta a oportunidade de entender como o relacionamento com o seu público deve ser direcionado para esse novo consumidor conectado, principalmente considerando o atual cenário da pandemia do novo coronavírus. A importância do estudo fica evidenciada no sentido em que contribui para alertar as empresas sobre a necessidade de serem comprometidas com o consumidor no atendimento das suas demandas e exigências. $\mathrm{O}$ consumidor é resultado dos meios que têm à sua disposição e, portanto, já não basta apenas vender o melhor produto, é necessário agir para conhecer esse consumidor inserido no novo cenário e criar estratégias para que as organizações possam atendê-los e conquista-los.

No que concerne ao método utilizado optou-se por um estudo de campo que investiga os fenômenos exatamente como ocorrem, sem qualquer intervenção significativa do pesquisador (Yin, 2010). Os resultados quantitativos foram apurados por meio do método de Pesquisa de Satisfação Costumer Satisfaction Score (CSAT), que de acordo com Vardanega (2019), consiste em perguntar para o cliente, como ele avalia a experiência com uma empresa/marca em escala linear e para os resultados qualitativos foi realizada uma análise de conteúdo.

\section{REVISÃO DA LITERATURA}

\subsection{Marketing Digital}

O avanço virtual foi importante para a expansão do marketing, tanto para alcançar um número maior de pessoas bem como para criar novas interações, mesmo com pessoas que se encontram distantes geograficamente. Diante disso, essa transformação modificou as ações de marketing e também os hábitos de compra dos indivíduos (Silva, 2018). Nos dias atuais é cada vez mais notório as mudanças no marketing tradicional para o digital nas empresas, tornando-se uma importante ferramenta de comunicação. Ao se expor na internet através das mídias sociais, a empresa acaba por ganhar espaço competitivo no mercado que está evoluindo continuamente (Caxias \& Rolim, 2019).

Implantar uma estratégia organizacional de mídia social que corresponda com êxito ao planejamento inicial é desafiante na ascensão do ambiente digital. Para Silva (2018) "as empresas, para garantirem sua permanência nele, precisam buscar se adaptar às mudanças, 
confrontando as novas exigências, disputando com a concorrência a conquista e retenção de clientes" (p.6). Ambas as estratégias, tradicional e digital, são consideradas relevantes quando o objetivo é alcançar o cliente e transformar toda esta ação em vendas. As empresas necessitam gerir suas atividades de modo responsável e dar importância às críticas dos clientes, gerando troca entre empresa e consumidor (Caxias \& Rolim, 2019).

Os ambientes competitivos do mundo globalizado forçam as empresas a melhorarem suas estratégias de inovação e gestão para alcançar resultados mais eficientes, eficazes e produtivos. Nesse sentido, o marketing digital é uma ferramenta de desenvolvimento para que as empresas possam trabalhar o comportamento de consumo incluindo seu público alvo nas etapas de compra e alcançando dados que podem consequentemente melhorar suas atividades (Redondo et.al., 2021; Medeiros \& Balduíno, 2019). Todavia, as empresas estão interessadas em monitorar as opiniões dos seus consumidores sobre seus produtos e serviços, buscando dessa maneira, criar estratégias para satisfazer e saciar suas profundas necessidades, tais como justiça social, econômica e ambiental.

Santos (2020) refere que o marketing digital, tem como principal condutor "as tecnologias de informação que the garantem dinamismo, velocidade e um alcance surpreendentemente maior do que a forma tradicional de marketing" (p.5). O autor destaca que o avanço tecnológico abriu espaço para as mídias sociais atuarem como espaço na promoção do marketing digital. Se por um lado as empresas estão focadas em se comunicar com a sociedade de forma efetiva, estratégica e respeitosa também compreendem a importância desse relacionamento na jornada de compra de seus clientes, e em suas atividades elas investem, cada vez mais, em estratégias voltadas à experiência do consumidor. Empresas, que antes eram vistas como sinônimos de lucratividade estão cada vez mais interessadas em promover e participar de ações que influenciem positivamente a vida das pessoas, ajudando com a evolução da comunidade em sua volta. Para alcançar essas necessidades surgiu o marketing social (Kotler \& Lee, 2019).

O termo marketing social surgiu em 1971 e seu uso foi principalmente para promover causas e comportamentos sociais (Kotler \& Lee, 2019). Um dos motivos que levaram a mudança de mentalidade foi a necessidade de se posicionar em prol de causas importantes para a sociedade.

Para alcançar o consumidor todas as estratégias de marketing são consideradas relevantes, 
gerando ação de venda para atrair novos clientes. No contexto, o marketing digital destaca-se como ferramenta para as empresas e não faz extinção do marketing tradicional, podendo ser agregado para gerar benefícios (Caxias \& Rolim, 2019). Em seu estudo, Santos (2020) entende que a relação do marketing digital com as mídias sociais "está ligada a estratégia utilizada para a divulgação de produtos e serviços realizada através da redes na internet auxiliando na promoção da marca com o objetivo de tornar $\mathrm{o}$ relacionamento entre a empresa e consumidor mais próximo" (p.13). Para o autor o consumidor influencia o marketing realizado através da internet, pois as mídias sociais se tornaram ferramentas cotidianas onde cada vez mais é utilizada para processos de compra e interação com as empresas.

\subsection{A comunicação e o marketing na conquista do consumidor}

Com a identificação de necessidades humanas e sociais o marketing vem evoluindo no decorrer das décadas buscando atender a satisfação dos clientes. É fundamental para o marketing conhecer as necessidades dos consumidores e da sociedade por que seu propósito é estar centrados em entender o motivo pelo qual buscam das empresas posicionamentos éticos que influenciam no seu modo de consumir, proporcionando às organizações novas estratégias de ação (Kotler \& Lee, 2019; Magids et.al., 2015).

A evolução das eras do marketing é compreendida através da concepção de consumo e consumidor. Essas duas noções são imprescindíveis para a compreensão não só do funcionamento dos processos que compõe o marketing, mas também pelo entendimento de como se dão as mudanças diante das necessidades que surgem na sociedade (Kotler et.al., 2012). O marketing 1.0 orienta-se para o desenvolvimento e vendas de produtos, pautando-se em uma proposição de valor mais funcional. Já o marketing 2.0 se fundamenta na satisfação e retenção do cliente criando diferenciação no produto e serviços com uma proporção de valor voltado para o funcional e emocional dos clientes. $\mathrm{O}$ marketing 3.0 tem por objetivo tornar o mundo melhor por meio das novas tecnologias. A era do marketing 4.0 tem como ponto central de atuação a internet, criando conteúdo com objetivo de atrair clientes com conteúdo relevante e de forma segmentada (Cordova et.al., 2020). O papel do marketing agora é fazer uma integração entre todos os caminhos que levam o cliente à compra. Portanto, o tradicional e o digital devem estar juntos, o consumidor precisa ter uma experiência única esteja ele online ou offline, as empresas precisam tornarem-se uma só. 
Atualmente, a literatura já traz o conceito de marketing 5.0. Segundo Kotler et.al., (2021), o marketing 5.0 agrega a tecnologia e o ser humano com o objetivo de aproximar marcas e consumidores de forma mais humanizada através da crescente utilização das redes sociais. Todavia, a evolução para a filosofia proposta pelo conceito do 'marketing 3.0' traduz o anseio contemporâneo de humanizar relações entre pessoas e organizações que vivem em um ambiente cada vez mais racional, complexo e tecnológico (Sato, 2011). Este conceito parece um caminho para viabilizar a atuação de empresas que necessitam crescer em um mundo com situações contrastantes, mercados saturados e desaquecidos por um lado, que demandam novas práticas de inclusão pelo consumo e participações para solução de problemas sociais existentes no mundo (Magids et.al., 2015).

A tecnologia da informação está presente na evolução do marketing como propulsor das dinâmicas que permitiram o empowerment dos clientes devido à facilidade de se adquirir informação e contato com as empresas. Com isso, o marketing vai se adequando a cada necessidade existente criando novos conceitos (Kotler et.al., 2012).

No contexto do marketing 3.0 as organizações já necessitam mudar a abordagem centrada no consumidor para a centrada no ser humano com valores emocional e espiritual que buscam fazer do mundo um lugar melhor (Ivo et.al., 2021), na qual a lucratividade está ligada à responsabilidade social corporativa, isso nada mais é do que as ações voltadas para as preocupações sociais inerentes ao novo contexto social e às formas de comunicação da empresa aos consumidores agregando valor a sociedade (Kotler et.al., 2012; Magids et.al., 2015. Esta nova definição revela que o marketing está pronto para abordar as implicações culturais que resultaram na formação da globalização, decorrente do avanço das tecnologias de informação gerando atividade, comunicação, entrega e troca de ofertas de produtos que têm valor para consumidores, clientes, parceiros e sociedade em geral, resolvendo as ansiedades dos seres humanos e o nível funcional, emocional, bem como espiritual das sociedades (Kotler et.al. 2012).

O crescimento da comunicação através das redes sociais serviu como base para essa mudança de comportamento abrindo novas formas pelas quais a sociedade pode levantar reivindicações e se envolver nas atividades empresariais. As mídias sociais deram aos consumidores um canal de comunicação que resultaram em mudanças nas expectativas sobre o que e como as empresas produzem e como elas se comportam, gerando sua 
identidade (Ferrell \& Pride, 2016). A identidade da marca tem a ver com o modo como a empresa se posiciona para estar presente na mente dos consumidores. Dessa forma, a marca será ouvida e notada em um mercado tumultuado, agindo singularmente e se mostrando relevante para as necessidades e os desejos racionais dos consumidores (Kotler et.al. 2012). Falar sobre a imagem da marca está relacionado com a conquista das emoções dos consumidores. "O valor da marca deve apelar para as necessidades e os desejos emocionais dos consumidores, ultrapassando, assim, as funcionalidades e características do produto" (Kotler et.al. 2012, p. 42).

Com a globalização as novas tecnologias surgiram potencializando o valor da informação e comunicação. No mundo dos negócios percebe-se que a comunicação empresarial é cada vez mais valorizada tornando-se o coração das grandes corporações, ajudando-as nas atividades rotineiras bem como a sua imagem (Yanaze, 2011; Neto, 2012). De acordo com Ferreira e Malheiros (2016, p. 28) "a comunicação empresarial abrange uma série de ações, atividades e estratégias que visam reforçar a imagem de uma empresa ou instituição com o seu público de interesse". Para os referidos autores, a comunicação corporativa é importante para ajudar a manter a imagem e reputação da empresa usando o conhecimento sobre a realidade empresarial e o ambiente externo como tendências culturais, sociais, políticas e econômicas para projetar sua voz a fim de se comprometer com responsabilidade social na sociedade e as causas emergenciais vividas por elas.

Assim, é importante que a comunicação empresarial seja considerada para todos os stakeholders como um investimento que irá proporcionar benefícios à organização, refletindo a base de relacionamento entre emissores e receptores de quaisquer organizações (Tomasi \& Medeiros, 2019). Segundo estes autores os consumidores estão mais interessados em saber se as atividades e projetos realizados pelas organizações geram impactos ambientais e sociais positivos. Com isso, as organizações precisam sempre se esforçar para levar a comunicação em todos os seus processos e ao seu público, uma vez que, torna-se mais frequente o engajamento dos mesmos. Todavia, os consumidores não querem mais saber apenas sobre as informações do produto. Esse novo consumidor quer ter uma ideia de que a organização se preocupa não apenas se o produto é bom, ele quer se envolver no processo de fabricação obtendo toda informação possível (Tomasi \& Medeiros, 2019; Mitre, 2018). Diante dessa nova realidade, o marketing vem agindo para enriquecer esse processo de comunicação entre empresa e consumidor. 


\subsection{O novo consumidor na sociedade de consumo}

Entende-se por sociedade de consumo a era atual do capitalismo em que o crescimento econômico e a geração de lucro e riqueza encontram-se constantemente relacionado no crescimento da atividade comercial e, consequentemente, do consumo (Souza, 2019). As pessoas são transformadas constantemente em simples consumidores movidos de acordo com os interesses do capital, que levam o indivíduo ao consumo imediatista, ou seja, a felicidade está contida no consumir nesse instante, com funcionalidade e rapidez, o que transforma em prazer o ato de consumir, e promove o aparecimento de "novas necessidades" a todo instante (Merlo \& Ceribeli, 2015).

Para Santos (2020), o número crescente de pessoas com acesso à internet, uma gama de canais de atendimento e interação proporciona ao consumidor voz ativa, com participação ativa no processo de desenvolvimento e criação das marcas. Com a facilidade desse campo de vendas, a internet gera quantidades variadas de concorrentes, fazendo com que estratégias de marketing digital sejam implantadas em busca de influenciar o consumo. $\mathrm{O}$ consumo trouxe não apenas benefícios para a sociedade, mas também inúmeras questões éticas, ambientais e sociais gerando a preocupação de muitos consumidores, surgindo daí um novo modelo de consumidor no mercado, o consumidor global, ou consumidor pósmoderno, mais consciente (Samara \& Morsch, 2010). Para Manes e Gomes (2019, p. 14), "o consumo consciente ocasiona nos consumidores reflexões intensas, mobilizando afetuosamente corações e mentes dos movimentos ambientais, das comunidades, dos governos e dos gestores de empresas", onde todos na sociedade têm papel fundamental no processo de consumo. $\mathrm{O}$ consumo se tornou um dos principais vetores da identidade, uma vez que congrega o poder sutil dos símbolos e das intenções pessoais com a materialidade das imagens socialmente construídas (Sousa, 2019).

O comportamento de compra do consumidor é visto como um propósito decisório. Independente do motivo que leva o consumidor a comprar as estratégias para a tomada de decisão é complexa, envolve etapas sequencias e integradas afetando a sua percepção e escolhas sobre suas aquisições, os deixando mais seletivos (Hawkins \& Mothersbaugh, 2019). O modo de selecionar, comprar e usar produtos e serviços pelo motivo de satisfazer suas necessidades e desejos é estudado como comportamento do consumidor que é influenciadopor fatores culturais, sociais e pessoais. É comum para o 
consumidor selecionar sua marcaconforme a sua personalidade, buscando também por atitudes responsavelmente sociais queestão relacionadas com a sua classe social e o estilo de vida da sociedade (Kotler \& Lee, 2019). Vale ressaltar, que as redes sociais trazem inúmeros benefícios aos consumidores, downloads, compras e fóruns são alguns deles disponíveis. Novos hábitos de consumo foram surgindocom o crescimento da internet e a chegada dos smartphones. Os clientes adotaram a conectividade, podem assim, lidar com dúvidas, queixas e obter informações que os ajudam no processo de decisão de compra em inúmeras plataformas disponíveis de relacionamento criados pelas organizações (Andrade, 2018).

Segundo Marques e Vidigal (2017) uma nova classe de consumidores surgiu preocupada em criar valores participando não só do papel do processo de consumo, mas também de produção, conceituados de "prosumer" que na tradução para o português é a união das palavras inglesas producer (produtor) e consumer (consumidor). Os prosumers dominam a tecnologia e a utilizam para se comunicar e fazer escolha, conectando-se com o mundo e influenciando quem os rodeia. A busca por valores nas marcas dos quais eles consomem é também uma característica fortemente ligada aos prosumers (Marques \& Vidigal, 2017).

Esse perfil de consumidor, que além de estar conectado nas mídias sociais, também funciona como uma rede de divulgação, circulação e julgamento de determinado produto, serviço ou marca. Sendo assim, a função dos prosumers no marketing vai além do aspecto do capital, eles adquirem status de agentes preocupados com as questões sociais, ambientais e científicas de determinada empresa, funcionando como uma espécie de juiz que determina o que está dentro ou fora das preocupações da sociedade (Marques \& Vidigal, 2017).

As novas tecnologias e as mídias sociais ajudam o marketing a coletar informações para entender o processo de consumo da sociedade e como se porta o consumidor diante de algumas questões. Nessa relação entre consumo e consumidor a comunicação entre a empresa e o cliente é fundamental já que é a partir de um processo comunicativo claro e assertivo que a empresa poderá criar suas estratégias, valores e missões (Ferrell \& Pride, 2016).

A história de uma marca não tem significado algum quando os consumidores não estão falando sobre ela. No marketing digital, a conversa é a nova propaganda e essa comunicação tem valiosa relevância. 


\section{ANÁLISE E DISCUSSÃO DOS DADOS}

O roteiro de entrevista feita com a proprietária da loja foi composto por 12 questões abertas, 3 de fatores demográfico e 9 sobre os objetivos da pesquisa, de maneira que a entrevistada pudesse estruturar seus pensamentos de forma orientada pelo entrevistador. Para os clientes foram feitas 9 perguntas, sendo 2 sobre fatores demográficos e 7 sobre fatores que buscam responder os questionamentos do objetivo da pesquisa. A estrutura das perguntas que envolvem os objetivos específicos da pesquisa está listada na Tabela 1.

\subsection{Análise qualitativa}

A análise qualitativa foi realizada através de entrevista aberta com a proprietária. Atualmente a loja tem apenas a proprietária como funcionaria direta e uma equipe de entregadores terceirizados para efetuar as entregas dos produtos.

A proprietária tem 27 anos, a sua formação é do ensino médio e atua há dois anos no mercado varejista de roupas femininas. A loja tem a sede física na sua residência, porém as vendas são realizadas na maioria via internet, diretamente na rede social Instagram.

$\mathrm{Na}$ entrevista foram obtidas todas as respostas das perguntas realizadas com a proprietária na busca de entender o que ela pensa sobre as práticas de venda online, como a comunicação, a imagem, os valores pregados pela marca e a experiência na jornada de compra, uma vez que mais consumidores estão aderindo ao processo online de compra.

$\mathrm{Na}$ questão 1, com o intuito de saber como se dá o processo de relacionamento entre empresa e cliente foi abordado como a internet ajuda a empresa no processo de comunicação com seus clientes e a proprietária respondeu que "minha principal estratégia de vendas é a interação com o cliente porque a internet tem facilitado o contato com a empresa na busca de respostas mais rápidas possível para seus questionamentos".

Com a facilidade de apresentar a sua opinião na internet as pessoas estão utilizando esse canal para expor as suas satisfações e insatisfações principalmente com uma empresa. $\mathrm{Na}$ questão 2, ao questionar a percepção sobre os comentários relacionados à loja nas redes sociais, a proprietária respondeu: 
Eu vejo de forma positiva. É bom para que os outros clientes vejam e confiem na minha empresa, pois geralmente os comentários são positivos. Quando negativo costumo responder com a solução ou um pedido de desculpa por que demonstra a empatia com a opinião dos clientes que não tiveram uma boa experiência coma marca.

Com o intuito de identificar quais os atributos que guiam o comportamento do consumidor para que a gestão possa ser mais assertiva foi perguntado (questão 3) o que a proprietária considera importante para conquistar o cliente no processo de compras pela internet e a resposta foi que a "clareza e valores, passando transparência nos processos que envolve as atividades e o preço justo para que os clientes sintam que estão fechando um bom negócio".

Entendendo que o cliente sabe onde localizar as informações necessárias sobre uma organização e que as empresas precisam ser o mais transparente possível sobre as suas atividades e objetivos, foi questionado (questão 4) que missão a empresa pratica, e a resposta dada foi "vender roupas femininas a preço justo para diversos padrões femininos".

Do mesmo modo, na questão 5, foi questionado que valores a emprea pratica com seus clientes, colaboradores e a proprietária respondeu que "clareza e honestidade com acliente. Valorização do empoderamento feminino". $\mathrm{Na}$ questão 6 foi perguntado para a proprietária quais as práticas para manter a boa imagem da loja e a resposta foi "preço justo e honestidade nas vendas".

Com o cliente constantemente conectado e mais perto das organizações na era da informação foi questionado (questão 7) se a proprietária considera que os clientes estão incluídos nos processos desenvolvidos pela loja e ela respondeu que:

Sim. Analiso o modelo e tamanho de roupas que as clientes mais costumam pedir para que eu possa solicitar mais tamanhos iguais. Costumo ouvir a opinião dos clientes que mais compram na loja sobre o que está mais em alta no mercado. Na entrega deixamos o cliente bem à vontade para escolher o dia e horário em que deseja receber. Essas atitudes trazem mais o cliente para próximo do negócio. 
Quando questionada (questão 8) sobre quais ações sociais existentes na comunidade a proprietária pratica ao realizar as atividades da empresa, e a mesma respondeu que:

\begin{abstract}
Alguns... infelizmente não é possível incluir todas. $\mathrm{O}$ empoderamento feminino é o que mais pratico nas minhas atividades. Vendo roupas para diversos formatos de corpos femininos. Atendemos mulheres que compram nossas roupas. Apoio outras mulheres que desejam aderir o mesmo negócio que o meu vendendo em atacado com desconto.
\end{abstract}

Na questão 9 quando perguntado sobre a importância de entender que o consumidor é um ser movido por emoções e que isso está envolvido no seu processo de compra ela respondeu que "total importância, não se vende apenas o produto, mas o bem-estar de se sentir mais bonita. O que percebo é que muitos clientes exigem mais das empresas sobre as atitudes dela e isso é considerado na hora de comprar".

Os resultados revelam que a proprietária da empresa estudada entende que o novo consumidor conectado busca mais do que apenas adquirir um produto ou serviço. $\mathrm{O}$ consumidor conectado quer ter uma experiência de compra satisfatória que condizem com os seus valores, buscando por marcas que se posicionem responsavelmente e que se comuniquem de forma clara e rápida sanando suas dúvidas assim como foi revelado pela literatura (Kotler et.al., 2012).

\title{
3.2 Análise quantitativa
}

$\mathrm{Na}$ elaboração do questionário da pesquisa, foi adotada uma escala intervalar do tipo Likert de cinco pontos para todas as questões, tendo suas classificações em " 1 = Nenhuma importância", "2 = Pouco importante", “3 = Indiferente", "4 = Importante" e "5 = Muito importante" associado ao método de Pesquisa de Satisfação CSAT, no qual consiste em realizar perguntas sobre situações onde a resposta é o nível de satisfação do respondente. A escala pode ser construída a partir de números podendo variar de 1 a 10 ou com palavras.

O CSAT mede como o cliente se sente após se comunicar com a organização. Uma vez que as pesquisas foram respondidas, é importante saber lidar com os dados que foram 
coletados, pois é um valor que indica quão satisfeitos seus clientes estão e como estratégia, obter os níveis altos de satisfação do cliente que deve ser o objetivo principal (Vardanega, 2019; Redondo, 2018). Uma boa pontuação CSAT reflete um serviço satisfatório oferecido por uma empresa que atende às expectativas dos consumidores e incentiva o cliente a se tornar um embaixador da sua marca.

A fórmula para cálculo do CSAT é aqui apresentada:

$$
\% \text { de CSAT }=\frac{\text { avaliações positivas }}{\text { total de avaliações }} \times 100
$$

A pesquisa foi lançada na página oficial da empresa no Instagram, e ficou disponível para 35 mil seguidores no período de abril a maio de 2020, tendo sido coletadas 182 respostas válidas.

Quanto ao perfil demográfico dos respondentes da pesquisa, do total de respondentes $79.7 \%$ é composto pelo sexo feminino e $20.3 \%$ do masculino. Como a empresa tem seus produtos voltados para mulheres a diferença já era esperada.

Para a escolaridade se constatou que $57.7 \%$ dos entrevistados têm nível superior de ensino, $32.4 \%$ possuem $2^{\circ}$ grau completo e $9.9 \%$ o $1^{\circ}$ grau completo. Esses dados demostram o grau de instrução que um indivíduo possui mediante questionamentos sobre determinados assuntos e que influenciaram nas respostas da pesquisa apresentada.

Depois das perguntas demográficas foram apresentadas questões que buscavam atingir os objetivos da pesquisa. 
Tabela 1 - Amostra quantitativa aplicada aos clientes

\begin{tabular}{|c|c|c|c|c|c|}
\hline QUESTÕES & \multicolumn{5}{|c|}{ TOTAL DE RESPOSTAS } \\
\hline & \multicolumn{5}{|c|}{$\begin{array}{l}(01=\text { Nenhuma importância, } 2=\text { Pouco } \\
\text { importante, } 3=\text { Indiferente, } \\
4 \text { = importante e } 05=\text { Muito importante })\end{array}$} \\
\hline & \multicolumn{5}{|c|}{182 participantes } \\
\hline & 1 & 2 & 3 & 4 & 5 \\
\hline $\begin{array}{l}\text { 1. Para você, o quão eficientes são os canais de } \\
\text { comunicaçãoutilizados pela loja? }\end{array}$ & 1 & 1 & 22 & 50 & 108 \\
\hline $\begin{array}{l}\text { 2. O quão você acha importante que a loja ofereça } \\
\text { resposta rápida aos clientes diante de uma notícia ou } \\
\text { fato que venhaquestionar suas atividades? }\end{array}$ & 0 & 1 & 7 & 33 & 141 \\
\hline $\begin{array}{l}\text { 3. Na sua opinião o quão a internet é importante ao decidir } \\
\text { comprar algo? }\end{array}$ & 1 & 2 & 10 & 50 & 119 \\
\hline $\begin{array}{l}\text { 4. O quão a imagem da marca loja influencia no seu } \\
\text { processo decompra? }\end{array}$ & 1 & 2 & 27 & 55 & 97 \\
\hline $\begin{array}{l}\text { 5. O quão importante é avaliar os comentários existente sobre } \\
\text { uma empresa nas redes sociais antes de a escolher para } \\
\text { seuprocesso de compra? }\end{array}$ & 0 & 1 & 6 & 30 & 145 \\
\hline $\begin{array}{l}\text { 6. O quão é importante as empresas envolvam seus } \\
\text { consumidoresem suas atividades? }\end{array}$ & 0 & 1 & 11 & 38 & 132 \\
\hline $\begin{array}{l}\text { 7. Para você, o quão é importante que uma empresa } \\
\text { realizepesquisa de satisfação com os clientes? }\end{array}$ & 0 & 0 & 4 & 23 & 155 \\
\hline
\end{tabular}

Na pergunta 1 quando questionados sobre a importância da eficiência dos canais de comunicação da empresa $59.3 \%$ consideraram que é muito importante e $27.5 \%$ importante.

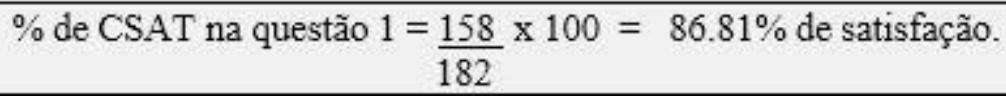

Mediante a utilização da internet para a comunicação com clientes foi questionado (questão 2), qual importância de respostas rápidas sobre comentários de outros 
consumidores que colocam em questionamento as atividades de uma marca e $77.5 \%$ consideram muito importante e $18.1 \%$ importante.

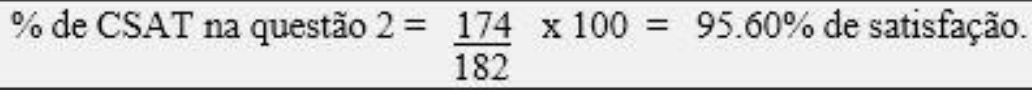

Os resultados obtidos na questão 1 e 2 demonstram que a maioria dos clientes que responderam à pesquisa percebem a importância dos processos de comunicação existentes nas organizações para a realização das suas atividades, conciliando com o que foi apresentado pela literatura (Tomasi \& Medeiros, 2019; Magids et.al., 2015).

Para avaliar a ajuda da internet na jornada de compra do consumidor (questão 3), 65.4\% dos respondentes consideram a internet muito importante na hora de decidir sobre uma compra e $27.5 \%$ julgam importante.

\begin{tabular}{|c|c|}
\hline \% de CSAT na questão $3=\frac{169}{182} \times 100=92.85 \%$ de satisfação. \\
\hline
\end{tabular}

Para complementar foi questionado (questão 4) sobre a importância da imagem como influência no processo de compra para seus clientes e $53.3 \%$ responderam que consideram muito importante para eles a reputação da marca, e 30.2\% julgam importante.

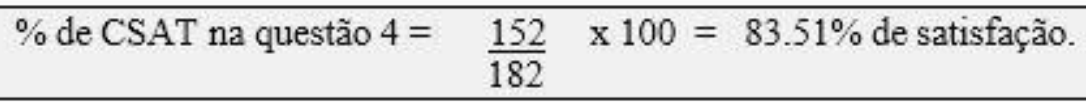

A questão 5 revela que $79.7 \%$ dos entrevistados consideram muito importante e $16.5 \%$ importante a avaliação de comentários existentes sobre as marcas nas redes sociais e aplicativos, somando assim um total de $96.2 \%$ de clientes que ao decidir comprar algo via internet irão buscar por críticas antes de comprar.

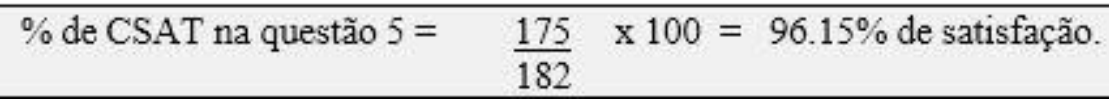

Na pergunta 6 questionou-se o quanto o consumidor da empresa julga importante que a marca inclua seu cliente em suas atividades, $72.5 \%$ apontaram considerar muito importante e $20.9 \%$ importante. 


\section{$\%$ de CSAT na questão $6=\frac{170}{182} \times 100=93.40 \%$ de satisfação}

Para finalizar foi questionado a importância da realização de pesquisa de satisfação para medir a satisfação dos clientes sobre as atividades da marca. Conforme respostas à pergunta 7 revelam, $85.2 \%$ dos respondentes consideram muito importante e $12.6 \%$ importante.

\begin{tabular}{|lll|}
\hline \% de CSAT na questão $7=\frac{178}{182}$ & $\times 100=97.80 \%$ de satisfação. \\
\hline
\end{tabular}

A pesquisa apresentou, para todas as questões, respostas consideradas positivas (Muito importante e Importante) na escala de Likert em comparação com as consideradas negativas (Pouco importante e Nenhuma importância) para os questionamentos, trazendo números importantes para as conclusões dos objetivos da pesquisa. Também apresentouem todas as análises de CSAT um índice de satisfação.

\section{CONCLUSÃo}

A importância de estudar as ações do Marketing nas organizações em meio a crescente utilização da internet no processo de compra se dá pela sua abordagem centrada na comunicação assertiva. A abordagem do marketing e suas evoluções humanizam a comunicação entre empresa e cliente buscando aprofundar a conexão emocional nas relações de consumo, a favor da colaboração para construção de um mundo melhor.

Na busca para descobrir como se dá o processo de relacionamento entre empresa e cliente, utilizando a internet como ferramenta dessa conexão, obteve-se que os consumidores reconhecem que a internet se tornou importante na busca para que sua voz seja ouvida. Os relacionamentos no mercado de consumo estão mais acessíveis, agora as organizações dispõem de inúmeros canais de comunicações contendo perfil em diversas redes sociais buscando sanar a demanda de contato por forma online. Conclui-se que a gestora da empresa colabora para que seus canais de contatos sejam eficientes visto que seus clientes reconhecem o quão a tecnologia facilita o processo de comunicação. 
Com relação à importância das práticas de gestão diante do comportamento do novo consumidor via internet foi identificado que os consumidores buscam por uma imagem positiva antes de consumir uma determinada marca concluindo que quaisquer atitudes da empresa sobre assuntos sensíveis na sociedade é contabilizado como indicador de decisão de compra.

Crises podem existir do nada em todas as sociedades, como exemplo a pandemia da Covid- 19, o papel dos gestores deve ser de inovação para adequar a demanda, pois o consumidor mais informado irá exigir da empresa atitudes que auxiliem na solução conjunta com demais instituições para o combate ao problema.

Os resultados revelaram que os desafios do marketing diante das mudanças no modo de consumir em meio a crises que podem colocar em dúvida as atitudes das organizações é prestar atendimento a um consumidor mais sensível que o normal mudando completamente sua abordagem.

Nesse objetivo foi concluído que a proprietária da empresa compreende a importância da comunicação para atender as demandas dos seus clientes e busca colaborar para uma jornada de compra mais assertiva, pois entende que seus consumidores o exigem. $\mathrm{O}$ conceito de Marketing é claro para a gestora, o que torna fácil moldar as atividades para alcançar os objetivos das várias abordagens. A comunicação que a internet proporciona é utilizada pela gestora como ferramenta para conquista e disseminação de uma imagem positiva da marca.

Com base nessas observações, pode-se demonstrar que os objetivos propostos na pesquisa foram concluídos. O marketing está agindo para atender a dinâmica do novo consumidor no contexto digital.

Com base na produção científica atual, esta pesquisa fornece evidências empíricas sobre a importância da humanização das relações entre empresa e clientes. O estudo evidencia para o mundo acadêmico e para a sociedade que as estratégias de marketing têm efeitos significativos nas relações de consumo uma vez que apresenta resultados que ligam consumidor e empresa em busca de uma civilização consumidora consciente. No geral, o capítulo oferece contribuições para gerentes e profissionais em geral, destacando importantes determinantes sobre a mais valia do uso da internet em uma conexão humanizada. 


\subsection{Limitações da pesquisa}

As limitações da pesquisa estão relacionadas com algumas dificuldades encontradas para a coleta de dados, tendo em vista o contexto delicado da pandemia Covid-19.

\subsection{Sugestões para futuras pesquisas}

Diante dos resultados encontrados, fica a sugestão como uma futura evolução da pesquisa o estudo das estratégias do marketing na comunicação virtual para melhorar a experiência de compra online e a imagem de marcas que tiveram as suas atividades questionadas ou afetadas negativamente por alguma questão de responsabilidade social.

\section{REFERÊNCIAS}

Andrade, R. J. S. (2018). Mídias sociais: análise do impacto nas vendas de empresas de médio porte, em Fortaleza (Monografia de bacharelato em administração) Centro Universitário Christus. Fortaleza.

Bezerra, A.C. V., Silva, C. E. M. da, Soares, F. R. G., \& Silva, J. A. M. da. (2020).

Fatores associados ao comportamento da população durante o isolamento social na pandemia de COVID-19. Ciência \& Saúde Coletiva, v. 25 (1), p. 2411-2421.

Caxias, N. M., \& Rolim, C. F.. (2019). Marketing tradicional vs. Marketing digital: uma questão de mudança nas pequenas empresas. Revista Científica Multidisciplinar Núcleo do Conhecimento. Ano 04, Ed. 06, Vol. 08, pp. 98-113.

https://www.nucleodoconhecimento.com.br/marketing/questao-de- mudanca?pdf=32257.

Cobra, M., \& Urdan, A. T. (2017). Marketing básico (5 ed.). São Paulo: Editora Atlas.

Cordova, G. S. M., Mônica C. A. L., Luteski, N. K. F., \& Nataly B. (2020). A nova era do Marketing 4.0 e a COVID-19: Impactos e mudanças causados em empreendimentos hoteleiros da cidade de Guarapuava-Paraná. In Atas do X Congresso brasileiro de engenharia de produção(online). https://aprepro.org.br/conbrepro/2020/anais/.

Creswell, J.W., \& Clark, V. L. P. (2013). Pesquisa de métodos mistos (2 ed.). Porto Alegre: Editora Penso.

Ferrell, O. C., \& Pride, W. M. (2016). Fundamentos de marketing: conceitos epráticas (6 ed.). São Paulo: Editora Cengage Learning.

Ferreira, P. I., \& Malheiros, G. (2016). Comunicação empresarial:planejamento, aplicação e resultado. São Paulo: Editora Atlas.

Hawkins, D. I., \& Mothersbaugh, D. L. (2019). Comportamento do consumidor construindo a estratégia de marketik (13 ${ }^{\mathrm{a}}$ ed.). Rio de Janeiro: Editora Elsevier.

Kotler, P., Kartajaya, H., \& Setiawan, I. (2012). Marketing 3.0: as forças que estão definindo o novo marketing centrado no ser humano. Rio de Janeiro: Editora Elsevier Kotler, P., Kartajaya, H., \& Setiawan, I. (2017). Marketing 4.0:do tradicional ao digital. Rio de Janeiro: Editora Elsevier. 
Kotler, P., Kartajaya, H., \& Setiawan, I. (2021). Marketing 5.0: technology for humanity. Nova Jersey: John Wiley \& Sons Inc

Kotler, P., \& Lee, N. R. (2019). Marketing social - Influenciandocomportamentos para o bem. São Paulo: Editora Saraiva.

Magids, S., Zorfas, A., \& Leemon, D. (2015). The new science of customer emotions. Harvard Business Review. https://hbr.org/2015/11/the-new-science-of-customer-emotions.

Manes, S. E. M. B., \& Gomes, R. L. R. (2019). O consumo consciente e desenvolvimento urbana sustentável. Revista Eumed.net.

https://www.eumed.net/rev/caribe/2019/06/desenvolvimento-urbana-sustentavel.html.

Marques, L. K. da S., \& Vidigal, F. (2017). Prosumers e redes sociais como fontes de informação mercadológica: uma análise sob a perspectiva da inteligência competitiva em empresas brasileiras. Universidade Fumec.

http://www.scielo.br/scielo.php?script=sci_arttext\&pid=S0103-

$37862018000100001 \& \operatorname{lng}=\mathrm{pt} \& \mathrm{nrm}=$ isso.

Medeiros, A.C., \& Balduino, M. A. C. (2019). O marketing 4.0 e a importância da comunicação com o novo consumidor nas redes sociais. Revista Cientifica Multidisciplinar Núcleo do Conhecimento. Ano 04, Ed. 09, Vol. 01, pp. 160-175. ISSN: 2448-0959. https://www.nucleodoconhecimento.com.br/marketing/marketing-4-0.

Merlo, E., \& Ceribeli, H. (2015). Comportamento do consumidor. Rio de Janeiro: Editora Gen.

Mitre, J. (2018). Satisfação do cliente como ponto de partida para aumentar a competitividade de um hospital especializado (Monografia de bacharelato em administração) Escola de administração de empresas de São Paulo da fundação Getúlio Vargas. https://bibliotecadigital.fgv.br/dspace/handle/10438/24750.

Neto, B. R. S. (2012). Comunicação corporativa e reputação:construção e defesa da imagem favorável. São Paulo: Editora Saraiva.

Peeri, N. C., Nistha, S., Rahman, M. S., Zaki, R., Tan, Z., Bibi, S., Baghbanzadeh, M., Aghamohammadi, N., Zhang, W., \& Haque, U. (2020). The SARS, MERS and novel coronavirus (COVID 19) epidemics, the newest and biggest global health threats: what lessons have we learned? International Journal of Epidemiology, V. 49(3), pp.717-726,

Redondo, R. C. P., Zapata, S. E. B., \& Palma, H. G. H. (2021). Impacto del marketing digital a las empresas colombianas emergentes. Revista Universidad \& Empresa, V.23(40), pp. 1-20. https://doi.org/10.12804/revistas.urosario.edu.co/empresa/a.9114.

Redondo, F. T. (2018). Desenvolvimento de um sistema de priorização assistido por inteligência artificial (Monografia), Universidade Federal de Santa Catarina.

https://repositorio.ufsc.br/handle/123456789/200006.

Rocha, I. J. K., Silva, M. B. \& Yuri, B. (2021). Excelência no atendimento ao Cliente: Uma Abordagem Histórica e Contemporânea. Revista de Administração do Cesmac. V. 10. https://revistas.cesmac.edu.br/index.php/administracao/article/view/1413.

Sato, S. K. (2011). Marketing 3.0: um novo conceito para interagir com um novo consumidor. Signos do Consumo, V.3 (2), pp. 243-245.

https://www.revistas.usp.br/signosdoconsumo/article/download/41814/45482.

Santos, N. V. dos (2020). Causas do marketing social em tempos depandemia da covid- $19 \mathrm{e}$ suas consequências no comportamento do consumidor do varejo. In: $C L A V$.

Santos, T. V. B. dos (2020). Marketing digital aplicado nas organizações (Monografia de bacharelato em administração), Centro Universitário do Planalto Central Aparecido dos 
Santos.

https://dspace.uniceplac.edu.br/bitstream/123456789/465/1/Thalia\%20Vilas\%20Boas

\%20dos\%20Santos_0005907.pdf.

Silva, A. P. (2018). Do marketing tradicional ao digital: uma análise dasestratégias de relacionamento da empresa SECAD no ambiente digital (Monografia de graduação em Relações Públicas), Universidade Federal do Rio Grande Do Sul, Porto Alegre. https://lume.ufrgs.br/handle/10183/192977.

Silva, L., Fernandes, R. A., \& Popp, T. R. (2020). O Comportamento do Consumidor no Cenário Atual de Pandemia. In: Atas do Seminário de Iniciação Científica e Seminário Integrado de Ensino, Pesquisa e Extensão, p. e25828-e25828.

Souza, F. G. P. (2019). Para além dos mercados: uma pesquisa Inter subjetivista sobre o consumo colaborativo(Tese), Universidade Estadual do Ceará, Fortaleza. http://www.uece.br/ppga/index.php/arquivos/doc_download/458-telefelipe-uma- pesquisaintersubjetivista-sobre-o-consumo-colaborativo.

Tomasi, C., \& Medeiros, J. B. (2019). Comunicação empresaria. (5ª ed.). São Paulo: Editora Atlas.

Vardanega, M. C. (2019). Análise do processo da pesquisa de satisfação de um centro de serviços compartilhados de um grupo de hospitais oftalmológicos do Brasil (Monografia graduação de Tecnologia em Gestão Hospitalar), Instituto Federal de Santa Catarina, Joinville. http://joinville.ifsc.edu.br/ bibliotecajoi/arquivos/tcc/gh2019/209159.pdf.

Yanaze, M. H. (2013). Gestão de marketing e comunicação: avanços eaplicações ( $2^{\mathrm{a}}$ ed.). São Paulo: Editora Saraiva.

Yin, R. K. (2010). Estudo de caso: planejamento e métodos. (4a ed.). Porto Alegre: Bookman.

\section{How to cite this article:}

Barroso, F. T. B. \& Oliveira, Z. M. (2021). O Marketing Digital na Conexão das Relações de Consumo. International Journal of Marketing, Communication and New Media, Vol. 9, No 17, $27-47$. 